\title{
A SOCIEDADE DO CONSUMO DURANTE O ISOLAMENTO SOCIAL: REFLEXÕES SOBRE PROTEÇÃO DE DADOS PESSOAIS, SUPERENDIVIDAMENTO E E-COMMERCE
}

\author{
Estéfani Luise Fernandes Teixeira* \\ Francine Cansi*
}

\section{RESUMO}

Este artigo reflete sobre o superendividamento pelo e-commerce no contexto de pandemia e isolamento social a partir da proteção de dados pessoais sensíveis dos consumidores. Para tanto, a partir duma leitura sociológica e usando o método funcionalista, examina-se a vulnerabilidade dos consumidores diante do tratamento de dados pessoais pelo varejo on-line com a acentuação trazida pela hiperconexão durante o isolamento social. Com o advento da Lei do Superendividamento, conclui-se que a educação financeira se mostra como solução para evitar ou diminuir conflitos consumeristas que levem ao superendividamento dos consumidores.

Palavras-chave: Vulnerabilidade do consumidor; Proteção de dados; E-commerce; Educação para o consumo; Lei n. 14.181/2021 (Superendividamento).

\section{CONSUMERISM SOCIETY DURING SOCIAL DISTANCING: REFLECTIONS ON PERSONAL DATA PROTECTION, OVER-INDEBTEDNESS AND E-COMMERCE}

\begin{abstract}
This article reflects on the over-indebtedness caused by e-commerce in the context of a pandemic and social distancing from the protection of consumers' sensitive personal data. To do so, from a sociological approaching and using the functionalist method, the vulnerability of consumers to the treatment of personal data by online retailers is examined, with the accentuation brought about by hyperconnection during social distancing. With the advent of the Over-indebtedness Law, it is concluded that financial education is a solution to avoid or reduce consumer conflicts that lead to over-indebtedness of consumers.
\end{abstract}

Keywords: Consumer vulnerability; Data Protection; E-commerce; Education for consumption; Law no. 14.181/2021 (Over-indebtedness).

\section{INTRODUÇÃO}

\footnotetext{
Mestranda em Direito pela UPF. Especialista em Direito e Processo do Trabalho PUCRS. Advogada e consultora. E-mail: estefani.f.teixeira@gmail.com.

** Doutora em Ciência Jurídica pela UNIVALI/SC. Doutora Internacional em Desenvolvimento Sustentável pela IUACA (Alicante, Espanha). Mestre em Desenvolvimento Regional: Estado Instituições e Democracia pela UNISC/RS. Especialista em Direito e Processo do Trabalho e Especialista em Processo Civil pela IMED/RS. Advogada. E-mail: francine@ctmadvocacia.com.
} 
A pesquisa analisa o aumento do superendividamento durante o isolamento social nas relações de consumo e o aumento vertiginoso do varejo on-line. $\mathrm{O}$ tema merece atenção frente à inserção dos meios tecnológicos para o consumo descomunal das pessoas no período pandêmico, ocasionado pela COVID-19 e a vulnerabilidade desses consumidores. O artigo aborda também as estratégias da indústria do varejo nas redes sociais para a manipulação e persuasão das pessoas, valendo-se da má-fé, para consumirem cada vez mais sem precisar.

Vive-se, hoje, em isolamento social, numa sociedade cercada das mais distintas tecnologias, o que potencializa a propagação de informação e conhecimento de forma instantânea, ao que se tem a manipulação dos algoritmos sobre os hábitos dos internautas hiperconectados. Passa-se por uma transformação cultural e social, em que as pessoas da mesma casa permanecem hiperconectadas, ocasionando na mistura das relações pessoais com as profissionais e tornando-se ainda mais recorrente a compra pelo comércio digital. Dessa forma, ocorreu grande aumento das pessoas superendividadas nesse período, ou seja, sem dinheiro para quitar seus débitos e sua subsistência. Nesse período, foi aprovada a Lei do Superendividamento, que dispõe sobre a prevenção e tratamento, como uma alternativa para evitar a exclusão social desses consumidores.

O presente artigo tem por escopo analisar a proteção dos dados dos titulares, a vulnerabilidade dos consumidores, as estratégias do varejo digital, a Lei do Superendividamento e a educação para um consumo inteligente. Diante disso, apresenta soluções cabíveis para os endividados, tutelando os direitos e garantias fundamentais e a essencialidade da proteção dos seus dados, bem como demonstrando que a educação para um consumo inteligente, por meio dos balcões dos consumidores, escolas, mídias digitais, entre outras, se torna imprescindível na situação vivida atualmente.

A globalização e os avanços trazidos pela tecnologia têm impactado a vida das pessoas. Nesse sentido, isso se deve ao crescimento célere no ambiente de consumo digital, ocasionando, por vezes, novos conflitos, pelo que se torna necessário repensar as soluções cabíveis para proporcionar um consumo saudável e inteligente. Desta forma, a educação financeira é o caminho mais acertado, porém, o consumidor também deve ser cauteloso a esse frenético consumismo eletrônico.

Em termos metodológicos, utilizou-se o método funcionalista de procedimento, objetivando analisar a Lei do Superendividamento a partir de sua função na sociedade. A seu 
turno, o método de interpretação jurídica é o sociológico, investigando como a tutela jurídica dos consumidores superendividados é havida no contexto social atual.

Espera-se, com o presente artigo, contribuir para a conscientização da realidade do comércio digital, manipulação e má fé do varejo, aumento de forma acentuada o superendividamento no período de isolamento social, especialmente tutelando direitos intrínsecos ao consumidor e com isso o protegendo. Igualmente, é esperado analisar alternativas inteligentes para ensinar as pessoas a consumir nas redes sociais como forma de informar e conscientizar as pessoas. Por fim, busca-se contribuir para tornar mais públicas a preocupação e as importantes campanhas que entidades estão propiciando nesse período para contribuir com um consumo inteligente. Destarte, diminuindo ou até mesmo eliminando o superendividamento no comércio digital.

\section{O NOVO PERFIL DE CONSUMO E CONSUMIDOR POR MEIO DO E- COMMERCE}

O espaço virtual é caracterizado como uma relação de anarquia. A cada minuto milhares de indivíduos criam e consomem um incalculável conteúdo digital na Internet que não tem limites e regras. A Internet é o maior espaço sem governo no mundo. Hoje, estamos na era do Big Data, em que "[...] o êxtase e o estado da arte de mineração dos dados, mais precisamente essa tecnologia, permite que um volume descomunal de dados seja estruturado e analisado para uma gama indeterminada de finalidades" (BIONI, 2018, p. 39).

Com o objetivo de ilustrar o Big Data, Bioni (2018, p. 42) explica uma ação de uma empresa por parte da varejista americana Target para identificar as consumidoras grávidas. Segundo a analogia estratégica da empresa no período gravídico as futuras mães consomem muito mais produtos:

\footnotetext{
A equipe de análise de Target conseguiu verificar que tal perfil de consumidoras adquiria uma determinada lista de produtos. Isso permitiu não só prever o estado da gravidez, mas também, o período da gestação para daí, lhes direcionar produtos de acordo com a respectiva fase da gravidez (BIONI, 2018, p. 42).
}

Dessa forma, o autor esclarece que "[...] os algoritmos foram programados para reestabelecer tal correlação, segmentando, dentre as milhares de consumidoras, aquelas com tal perfil para fins de ação publicitária” (BIONI, 2018, p. 42). 
Há um controle hierárquico que permite ações fraudulentas, de persuasão e de controle da vida de forma instantânea e descomunal. Nesse ponto, viola vários direitos e garantias fundamentais elencados na Constituição de 1988, como privacidade e intimidade, por meio do compartilhamento sem autorização dos titulares de seus dados pessoais e sensíveis.

A adesão em massa da Internet é sem precedentes, pelo que promove uma transformação cultural, social, econômica e até política, sendo globais os seus efeitos. O crescimento exponencial desse espaço virtual sem regras gera insegurança nas pessoas, no caso em comento, nos consumidores.

Acrescenta-se que se destina a despertar o desejo, seduzindo os consumidores para comprarem cada vez mais e mais sem necessidade para “[...] não parar a caça global de lucros".

Nossa sociedade é uma sociedade de consumo, pois "Quando falamos de uma sociedade de consumo, temos em mente algo mais que a observação trivial de que todos os membros dessa sociedade consomem; todos os seres humanos, ou melhor, todas as criaturas vivas "consomem desde tempos imemoriais" (BAUMAN, 2012, p. 83). Nesse sentido, Bauman (2012, p. 84) salienta que:

O que temos em mente é que a nossa é uma "sociedade de consumo" no sentido, similarmente profundo e fundamental, de que a sociedade dos nossos predecessores, a sociedade moderna nas suas camadas fundadoras, na sua fase industrial, era uma "sociedade de produtores". Aquela velha sociedade moderna engajava seus membros primordialmente como produtores e soldados; a maneira como moldava seus membros, a "norma" que colocava diante de seus olhos e os instava a observar, era ditada pelo dever de desempenhar esses dois papéis. [...] A maneira como a sociedade atual molda seus membros é ditada primeiro e acima de tudo pelo dever de desempenhar o papel de consumidor. A norma que nossa sociedade coloca para seus membros é a da capacidade e vontade de desempenhar esse papel.

Em outra obra, Bauman (2012, p. 35) coloca:

Aparentemente, o consumo é algo banal, até mesmo trivial. É uma atividade que fazemos todos os dias, por vezes de maneira festiva, ao organizar um encontro com os amigos, comemorar um evento importante ou para nos recompensar por uma realização particularmente importante - mas a maioria das vezes é de modo prosaico, rotineiro, sem muito planejamento antecipado nem reconsiderações. Se reduzido à forma arquetípica do ciclo metabólico de ingestão, digestão e excreção, o consumo é uma condição, e um aspecto, permanente e irremovível, sem limites temporais ou históricos; um elemento inseparável da sobrevivência biológica que nós humanos compartilhamos com todos os outros organismos vivos. Visto dessa maneira, o fenômeno do consumo tem raízes tão antigas quanto os seres vivos - e 
com toda certeza é parte per manente e integral de todas as formas de vida conhecidas a partir de narrativas históricas e relatos etnográficos. Ao que parece, plus ça change, plus c'est la même chose... Qualquer modalidade de consumo considerada típica de um período específico da história humana pode ser apresentada sem muito esforço como uma versão ligeiramente modificada de modalidades anteriores. [grifos do autor]

O autor sustenta que, em vista disso, nesse campo "[...] a continuidade parece ser a regra; rupturas, descontinuidades, mudanças radicais, para não mencionar transformações revolucionárias do tipo divisor de águas, podem ser (e com frequência são) rejeitadas como puramente quantitativas, em vez de qualitativas" (BAUMAN, 2012, p. 34-35). Ressalte-se que o consumo, nessa perspectiva,

[...] deixa pouco espaço para a inventividade e a manipulação, isso não se aplica ao papel que foi e continua sendo desempenhado pelo consumismo nas transformações do passado e na atual dinâmica do modo humano de ser e estar no mundo. Em particular, não se aplica ao seu lugar entre os fatores determinantes do estilo e da qualidade da vida social e ao seu papel como fixador de padrões (um entre muitos ou o principal) das relações inter-humanas (BAUMAN, 2012, p. 35).

Em virtude da COVID-19, ocorreu vertiginoso aumento no varejo por meios digitais, acarretando profunda mudança no modo de consumir. Empresas que vendem seus produtos pela Internet estatisticamente objetivarão uma vasta lucratividade. Dentro de uma perspectiva de análise rasa, pode-se dizer que foi bom para o comércio que se reinventou. Assim, muitos de seus empregados não perderam seus empregos, levando a este novo perfil de consumidor que, devido às tecnologias de comunicação e informação, tem acesso facilitado e instantâneo.

Por essa razão, empresas de varejos buscam estratégias inteligentes para induzir o indivíduo ao consumo constante, por vezes, de produtos que os compradores não precisam, pelo poder de persuasão, violação dos dados pessoais dos titulares, privacidade, intimidade e manipulação por meio dos algoritmos nas redes sociais. O consumidor recai na compra desnecessária, pensando ser uma necessidade ou para obter uma validação com aquela compra, o que, em muitos casos, ocasiona o superendividamento.

Os transtornos psiquiátricos de ansiedade, depressão, entre outros - cada vez mais comuns na sociedade moderna -, tornam ainda mais fértil o terreno para o êxito da indústria do comércio digital, uma vez que grande parte das pessoas vislumbram a felicidade por meio do consumo digital. Tal sensação acaba por ser demasiadamente volátil e estimula cada vez mais um ciclo vicioso ao consumismo. 
Nesse sentido, o novo perfil de consumo e consumidor é do consumo desenfreado e muitas vezes desnecessário. A mudança das relações de consumo para o mundo hiperconectado transformou o comportamento do consumidor, essencialmente no que concerne a forma como ele compra, busca meios de entretenimento, se comunica e paga pelos bens e serviços adquiridos sem perceber o valor saindo da sua conta bancária. Torna-se mais facilitada a persuasão e manipulação do varejo para com esse consumidor, pois acaba comprando por impulso.

Han (2019, p. 49), nesse contexto de sociedade adoecendo - com sérios transtornos de ansiedade, estresse, depressão, entre outras enfermidades -, aduz que

[...] o verbo modal que define a sociedade do desempenho não é o "dever" freudiano, mas o poder hábil (Können). Essa mudança social traz consigo uma reestruturação também no interior da psique. O sujeito do desempenho pós-moderno possui uma psique bem diferente do sujeito obediente, abordado pela psicanálise de Freud.

[...] o aparato psíquico de Freud é dominado pelo medo e pela angústia frente à transgressão. Desse modo, o 'eu' se transforma num local de medo e angústia. Mas isso já não se aplica ao sujeito de desempenho da pós-modernidade. Esse é um sujeito da afirmação.

Por conseguinte, a globalização e as novas relações culturais, econômicas e sociais por meio do ciberespaço é instantânea, célere, irreversível, irrefreável e sem precedentes. O autor Hui (2020, p. 15-16) salienta que,

[...] em primeiro lugar, estamos testemunhando os últimos momentos da globalização unilateral. Até agora, a assim chamada "globalização" tem sido em sua maior parte um processo que emana de um só lado e traz consigo a universalização de epistemologias particulares e, através de meios tecnoeconômicos, a elevação de uma visão de mundo regional ao status de metafísica supostamente global.

[...] a espécie humana se encontra diante da crise do antropoceno. A Terra e o cosmos foram transformados em um imenso sistema tecnológico - o ápice da ruptura epistemológica e metodológica a que chamamos de modernidade.

Diante do exposto, realizada essa reflexão sobre a ascensão digital, o novo perfil das relações de consumo e do consumidor no comércio digital se passa analisar a vulnerabilidade dos consumidores nas mídias digitais e o aumento do superendividamento dos brasileiros, principalmente no período de isolamento social.

\section{GLOBALIZAÇÃO: VULNERABILIDADE DOS CONSUMIDORES NAS MÍDIAS DIGITAIS E SUPERENDIVIDAMENTO DOS BRASILEIROS}


Na contemporaneidade, ocorreu um aumento do faturamento do comércio eletrônico, conforme supracitado, e da manipulação dos dados na Internet, tornando o consumidor um alvo da má-fé da indústria do e-commerce. Assim, o poder de decisão do consumidor está pautado não somente pelo seu livre arbítrio e sim pela manipulação e estratégias cada vez mais acentuadas e persuasivas do varejo online, logo se beneficiando da vulnerabilidade da parte mais frágil da relação. Assim, torna-se evidente a mudança que as redes sociais proporcionaram no que tange às formas e relacionamentos de consumo no comércio nas plataformas digitais, com isso influenciando significativamente o consumidor.

As TICs, no mundo pós-moderno, permitem aos indivíduos acesso mais facilitado à informação e aumento de conhecimentos e relacionamentos. Quando conjugada à publicidade e marketing num mundo de padrões capitalistas, esse cenário tende a levar os trabalhadores ao labor intenso, sem direito à desconexão, ocasionando doenças de cunho psicológico, sendo a mais habitual a síndrome de burnout, devido a essa hiperconexão nesta modalidade da nova escravidão nas relações econômicas, sociais e humanas. Verifica-se ter ocorrido uma transformação nas relações de trabalho e de consumo ao se permitir que o homem trabalhe cada vez mais e mais rápido, rompendo as barreiras do tempo e do espaço e, claro, suscitando em conflitos.

O chamado fenômeno da globalização permite esse distanciamento entre as pessoas (ou a interação virtual como avatares) por meio dos aparatos tecnológicos e Internet, propiciando as relações instantâneas virtuais. No caso em comento, entre o comércio online e consumidores. Neste sentido, Han (2019, p. 53) sustenta que

[...] o sentimento de ter alcançado uma meta não é "evitado" deliberadamente. Ao contrário, o sentimento de ter alcançado uma meta definitiva jamais se instaura. Não é que o sujeito narcisista não queira chegar a alcançar a meta. Ao contrário, não é capaz de chegar à conclusão. A coação de desempenho força-o a produzir cada vez mais. Assim, jamais alcança um ponto de repouso da gratificação. Vive constantemente num sentimento de carência e de culpa. E visto que, em última instância, está concorrendo consigo mesmo, procura superar a si mesmo até sucumbir. Sofre um colapso psíquico, que se chama de burnout (esgotamento). O sujeito do desempenho se realiza na morte. Realizar-se e autodestruir-se, aqui, coincidem.

Destarte, a globalização tem sido pesquisada e conceituada por muitos autores. De Mais (1991, p. 186-194) trabalha com dez fases de globalização, qualificando de acordo com 
os objetivos propostos nas diversas fases de expansão. Castells (2001, v. 1. p. 96) estuda a globalização econômica, sendo a expansão do trabalho o ponto comum entre os autores. Bauman (2012, p. 6) pontua que, para determinado grupo, a globalização

[...] é o que devemos fazer se quisermos ser felizes; para outros, é a causa da nossa infelicidade. Para todos, porém, "globalização" é o destino irremediável do mundo, um processo irreversível; é também um processo que nos afeta a todos na mesma medida e da mesma maneira. Estamos todos sendo "globalizados" — e isso significa basicamente o mesmo para todos.

No mundo das redes sociais e publicidade, a exponencialidade do fluxo e da agregação dos dados pessoais torna-se ainda mais evidente entre pessoas na Internet. Bioni (2018, p. 28) aduz que "[...] o zero-price advertisement buniness model quebrou com a tradicional bilateralidade das relações de consumo, tornando-as plurilaterais". [grifos do autor] Ainda nessa linha, sustenta que “[...] há uma complexa rede de atores que operacionalizam a entrega da publicidade on-line para rentabilizar os serviços e produtos 'gratuitos' on-line".

Da mesma forma, realizar o processamento dos dados pessoais dos titulares mantendo uma vasta base de dados e segmentando determinados grupos de futuros consumidores para aquele perfil de compra, empresa, consumo, de forma que se alcance o resultado desejado.

Bioni (2018, p. 33) explica que o "[...] o zero-price advertisement business model consiste em um novo tipo de negócio, que esconde uma série de sujeitos para a sua operacionalização. É uma intrincada e complexa rede de atores que atua colaborativamente para a entrega de publicidade direcionada (comportamental)". [grifos do autor] Nesse ínterim, o autor utiliza como exemplo para “[...] ilustrar esse modelo de negócio encorados na publicidade comportamental os aplicativos de mensageria WhatsApp pelo Facebook, na ordem de US 19 bilhões de dólares - uma das maiores transações da história desse ramo". Saliente-se que o WhatsApp não surgiu somente como um aplicativo de mensagens privadas, mas também com a promessa que os dados pessoais dos titulares não seriam revertidos para fins de publicidade comportamental.

Segundo o autor, é por essa razão que é paradigmática a aquisição do WhatsApp pelo Facebook, pois muito explica a respeito da promulgada monetização dos dados pessoais, especialmente como estratégia comercial que influencia toda a celeuma regulatória no que 


\title{
A SOCIEDADE DO CONSUMO DURANTE O ISOLAMENTO SOCIAL: REFLEXÕES SOBRE PROTEÇÃO DE DADOS PESSOAIS, SUPERENDIVIDAMENTO E E-COMMERCE
}

tange à proteção dos dados pessoais (BIONI, 2018, p. 35). Nesse contexto, podemos concluir que a Internet é um campo fértil para a violação da privacidade, intimidade e vazamento dos dados pessoais, de forma a infringir os dispositivos da Constituição de 1988, como exemplo, o direito fundamental à proteção de dados.

Da mesma forma, torna-se clara a vulnerabilidade do consumidor frente a manipulação de dados na Internet, pois nos novos tempos as TICs nos permeiam por meio de nossos aparelhos tecnológicos: celular, notebook, computador, tablet etc., os quais são nossos novos "membros" e hoje muitas pessoas são dependentes dessas tecnologias, seja para o trabalho, lazer, consumo, ócio, numa gama de possibilidades. Além disso, o próprio Código de Defesa do Consumidor apresenta tal vulnerabilidade. Nessa linha, Bauman (2012, p. 17) ressalta que:

\begin{abstract}
Os encontros dos potenciais consumidores com os potenciais objetos de consumo tendem a se tornar as principais unidades na rede peculiar de interações humanas conhecida, de maneira abreviada, como "sociedade de consumidores". Ou melhor, o ambiente existencial que se tornou conhecido como "sociedade de consumidores" se distingue por uma reconstrução das relações humanas a partir do padrão, e à semelhança, das relações entre os consumidores e os objetos de consumo. Esse feito notável foi alcançado mediante a anexação e colonização, pelos mercados de consumo, do espaço que se estende entre os indivíduos - esse espaço em que se estabelecem as ligações que conectam os seres humanos e se erguem as cercas que os separam. Numa enorme distorção e perversão da verdadeira substância da revolução consumista, a sociedade de consumidores é com muita frequência representada como se estivesse centralizada em torno das relações entre o consumidor, firmemente estabelecido na condição de sujeito cartesiano, e a mercadoria, designada para o papel de objeto cartesiano, ainda que nessas representações o centro de gravidade do encontro sujeito-objeto seja transferido, de forma decisiva, da área da contemplação para a esfera da atividade.
\end{abstract}

A seu turno, Canto (2019, p. 323) aponta que as tecnologias

[...] levaram para os lares das pessoas atividades que antes eram restritas a horários e pontos comerciais, tornando-as ubíquas e desmaterializadas. "Agora é possível procurar, encomendar, pagar, receber e utilizar vários itens, tais como livros, música, e outros produtos digitais, em dispositivos portáteis que podem ser usados em qualquer lugar - no jardim, no supermercado, no metrô". Apaga-se a fronteira entre espaços de convivência públicos e privados, permitindo que as tecnologias móveis e cada vez mais portáteis adentrem na esfera doméstica. Assim, o computador e a Internet geraram uma "explosão de opções ao consumidor em relação, não somente ao que e quanto comprar, mas também onde, como, e quando comprar". Com isso, estabelecimentos comerciais tradicionais iniciam a migração para a web, ao mesmo tempo em que surgem lojas puramente virtuais, e começam a competir pela atenção dos consumidores. Concomitantemente, as tecnologias antes fragmentadas de texto, áudio, vídeo, Internet e banda larga são integradas em dispositivos multiplataformas, tais como computadores, smartphones, tablets, plataformas de jogos e outros tantos 
dispositivos que se tornam instrumentos essenciais a seus usuários. Mesmo os consumidores mais relutantes no uso dessas novas tecnologias acabam cedendo a elas, dado o design simplificado e intuitivo dos produtos e serviços desenvolvidos, bastando clicar com o mouse ou pressionar botões nas telas sensíveis ao toque para que aparelhos "inteligentes" façam todo o resto. Desse modo, pretende-se que desde crianças até idosos consigam usar smartphones e buscadores na web, tendo como resultado a ampliação e o aprofundamento da comunidade on-line.

Nesse diapasão, resta claro que o consumidor perdeu o seu poder de decisão devido esse bombardeio constante de publicidade excessiva para o consumo que, por vezes, é desnecessário. A Internet - o mundo das redes e mídias digitais -, conforme anteriormente descrito, tornou-se espaço sem governo, sem regras e com poucas perspectivas de regulação, tendo em vista que cada país tem sua Constituição, normas e diretrizes. Sendo assim, por ora, não há possibilidades de uma constituição digital, no máximo a regulação de cada país, tais como a Lei Geral de Proteção de Dados no Brasil e a General Data Protection Regulation GDPR na União Europeia, entre outros.

Todavia, faz-se necessário colocar limites na publicidade, pois esta é hoje um dos principais meios para o capitalismo conquistar seu objetivo. Assim, visando sempre à lucratividade versus a vulnerabilidade do consumidor digital, tem-se maior preocupação em tutelar os direitos e garantias desses consumidores, revelando-se como desafio para quem trabalha com Direito Consumerista, pois não há uma imposição de limites para obtenção de lucros. Deste modo, são desrespeitados os valores sociais dos consumidores. A consequência da violação de uma gama de direitos intrínsecos a pessoa humana, é o superendividamento.

O CDC dispõe em seu artigo 54-A, § $1^{\circ}$, que superendividamento é a “[...] impossibilidade manifesta de o consumidor pessoa natural, de boa-fé, pagar a totalidade de suas dívidas de consumo, exigíveis e vincendas, sem comprometer seu mínimo existencial". De plano já restam excluídas as pessoas jurídicas do conceito. A seu turno, Marques, Lima e Vial (2021, p. 3) definem o superendividamento “[...] como a impossibilidade global do devedor-pessoa física, consumidor, leigo e de boa-fé, de pagar todas as suas dívidas atuais e futuras de consumo (excluídas as dívidas com o Fisco, oriunda de delitos e de alimentos)". Nessa linha, Canto (2019, posição 3912) afirma que

A experiência brasileira recomenda que matérias que sejam da essência das relações de consumo (como o crédito, o superendividamento e o comércio eletrônico) façam parte do corpo do CDC e beneficiem-se de sua estabilidade legislativa e principiologia microssistêmica. Evita-se, dessa maneira, que se formem, pela 
especialização, novos microssistemas, verdadeiros guetos normativos, divorciados, e até antagônicos ao espírito e letra do CDC.

Mister registrar que "[...] é preciso estabelecer um sistema de tratamento do superendividamento para os consumidores pessoas físicas no Brasil que não seja a simples exclusão da pessoa da sociedade" (MARQUES; LIMA; VIAL, 2021, p. 7). Do mesmo modo, em tempos de pandemia de hiperconexão e isolamento social, aumentaram os casos de superendividamento nas plataformas digitais. Nesse sentido, se torna necessário averiguar o caso concreto de cada consumidor e investir em educação financeira e consumo inteligente para essa pessoa conseguir quitar suas dívidas e saber se blindar de possíveis compras desnecessárias e dívidas em sua vida econômica.

Portanto, nas próximas linhas será analisado a educação para o consumo inteligente e consequentemente a Lei n. 14.181/2021, intentando a prevenção e tratamento para o superendividamento.

\section{EDUCAÇÃO PARA O CONSUMO INTELIGENTE: A LEI N. 14.181/2021 PARA PREVENÇÃO E TRATAMENTO PARA O SUPERENDIVIDAMENTO}

Esse movimento que fizemos compulsoriamente por conta da pandemia nos fez avançar ou regredir? A resposta pode ser encontrada ao começarmos a refletir sobre as plataformas que deram sustentação de uma forma ou outra aos diferentes processos da ação humana no mundo. Muitos consumidores e empresários precisaram se reinventar por meio da criatividade, apesar de todas as ponderações e reflexões realizadas no presente artigo.

Com a reinvenção e o novo modelo de negócio (e-commerce), é nítido o aumento das pessoas superendividadas e se torna necessário educar para consumir; refletir sobre o consumo inteligente; revenir o superendividamento; e tratá-lo. No que tange à educação, a Constituição de 1988 , em seu art. $4^{\circ}$, inc. IX, dispõe como princípio a educação e formação de consumidores e fornecedores com os seus direitos e deveres para melhoria das relações de consumo.

Além do CDC, existe o plano nacional de consumo e cidadania com as diretrizes da educação para o consumo, bem como evidencia os conflitos ocasionados e como evitá-los por meio da educação do consumidor. Percebe-se a importância de educar o consumidor e que esta educação deva se estender nas escolas, no ensino fundamental básico, superior, nos 
balcões do consumidor, visto que seja importante abordar desde cedo a educação financeira, formando o indivíduo para o mundo digital e as novas formas de consumir.

A educação em todos os sentidos é de grande importância, tanto do ponto de vista individual quanto do coletivo. O acesso à informação fidedigna e o bom esclarecimento, em escolas, faculdades, balcões, materiais lúdicos, cartilhas, nas plataformas digitais, palestras, entre muitas possibilidades, é o caminho para mudarmos a realidade do superendividamento dos consumidores jovens, adultos, idosos, de todas as classes e faixa etária.

O Banco Central do Brasil (2014, v. I, p. 8) contribuiu com um guia de excelência de educação financeira do consumidor, dispondo que

[...] a educação financeira é mais eficaz quando o consumidor está motivado por certa circunstância de vida, como a necessidade de adquirir uma casa. Nesse momento, chamado "teachable moment", ele estará mais "aberto" para aprender qual a melhor forma de gerenciar sua vida financeira e avaliar opções de financiamento. [grifos do autor]

Todavia, faz-se necessário propor políticas públicas em um campo multidisciplinar, bem como observar os indivíduos por serem diversificados e para melhor atender suas demandas. Assim, de fato a educação para o consumo é muito complexa e deve ser abranger uma gama de diversas áreas e setores. Importante tratar a defesa do consumidor nesse viés. Sendo assim, o Banco Central do Brasil (2014, v. I, p. 10) acrescenta que,

[...] com efeito, a participação das instituições financeiras é fundamental no processo de educação financeira, pois têm posição privilegiada para atuar como vetor de disseminação, uma vez que estão no "momento e local certos" para apresentar aos consumidores opções de produtos e serviços financeiros, explicando suas características, benefícios, custos e riscos, inclusive abordando temas relacionados à gestão de finanças pessoais. Dessa forma, informação e orientação no momento da oferta de um serviço financeiro podem contribuir para que o consumidor tome melhores decisões em relação a sua aquisição, mais ciente dos custos e dos riscos envolvidos na contratação, gerenciando melhor, assim, sua vida financeira.

Nesse contexto, necessário dissertar sobre a Lei n. 14.181/2021 (BRASIL), a qual modifica o CDC e o Estatuto do Idoso para aperfeiçoar a disciplina do crédito ao consumidor e dispor sobre a prevenção e o tratamento do superendividamento. A lei em comento entrou em vigor em julho de 2021, ficando conhecida como a Lei do Superendividamento, e tem o condão de proteger os consumidores com diversas dívidas ao criar mecanismos para barrar as propostas estratégicas das instituições financeiras. Destarte, a Lei do Superendividamento 
[...] criou um instrumento de renegociação em bloco das dívidas nos tribunais estaduais de Justiça. Num procedimento semelhante às recuperações judiciais realizadas por empresas, a pessoa física pode fazer uma conciliação com todos os credores de uma única vez, criando um plano de pagamentos que caiba no bolso (MÁXIMO, 2021).

A lei em tela objetiva realizar a renegociação de dívidas de consumo, sendo elas boletos e carnês, contas de água e luz, empréstimos, crediários e parcelamentos em geral. Tanto as contas vencidas quanto aquelas a vencer fazem parte da lista de dívidas contempladas pela lei (BRASIL, 2021).

Importante ressaltar a prevenção e o tratamento para o superendividamento. Conforme citado, o tratamento do superendividamento deve ser abordado pela questão da educação financeira. Assim, “[...] o fenômeno social, econômico e jurídico do superendividamento dos consumidores é mundial e foi agravado com a pandemia de Covid19” (MARQUES; LIMA; VIAL, 2021, p. 6). Ainda se tratando da proteção de dados pessoais, torna-se essencial o que Sarlet (2021, p. 21) diz:

[...] a proteção de dados pessoais alcançou uma dimensão sem precedentes no âmbito da chamada sociedade tecnológica, notadamente a partir da introdução do uso da tecnologia da informática e da ampla digitalização que já assumiu um caráter onipresente e afeta todas as esferas da vida social, econômica, política e cultural contemporânea no mundo, fenômeno comumente designado de Ubiquitous Computing.

Importante ressaltar que a Lei Geral de Proteção de Dados objetiva proteger os dados dos titulares e entrou em vigor no ano de 2021. A proteção de dados pessoais emerge no âmbito da sociedade de informação como possibilidade de tutelar direitos da personalidade do indivíduo contra os potenciais riscos a serem causados pelo tratamento de dados pessoais. É preciso levar em conta, nessa seara, que a proteção de dados não se resume à salvaguarda de dados, mas à proteção do titular destes mesmos dados.

Nesse contexto, percebe-se que as relações de trabalho, a tecnologia e a proteção de dados se entrecruzam de forma que o "desenvolvimento tecnológico" se revela como um grande catalisador de mudanças no tecido social e cultural, chegando a pautar uma nova sociedade: a sociedade da tecnologia de informação e comunicação (SILVA, 2019, p. 13).

Sendo assim, uma vez compreendida esta interação, torna-se imperioso munir-se de uma legislação que visa proteger os dados, resguardando garantias e direitos fundamentais. A 
proteção de dados pessoais, em síntese, é a defesa dos dados de uma pessoa, mormente os que dizem respeito aos direitos de personalidade, direitos humanos e direitos fundamentais. A sua função, em última análise, não é a de proteger os dados, mas a pessoa que é titular desses dados. Está-se falando, desta forma, de proteção da pessoa humana, sobretudo a partir do resguardo dos seus direitos de personalidade, essencialmente, mediante proteção informacional. Nesse contexto, Tucci $(2017$, p. 6) aduz que o superendividamento

[...] trata-se da situação em que o consumidor, na qualidade de pessoa física, imbuído de boa-fé, não detém os meios necessários para pagar de forma integral suas dívidas contraídas no mercado de consumo. Vale ressaltar que o consumidor fica impossibilitado de efetuar o pagamento das dívidas, pois se assim o fizer, poderá haver o comprometimento do mínimo existencial.

Neste ínterim, importante trazer a letra do art. 54-A, caput e $\S 1^{\circ}$, do CDC (BRASIL, 1990) após a alteração trazida pela da Lei do Superendividamento, que assim dispõe:

Art. 54-A. Este Capítulo dispõe sobre a prevenção do superendividamento da pessoa natural, sobre o crédito responsável e sobre a educação financeira do consumidor.

$\S 1^{\mathrm{o}}$ Entende-se por superendividamento a impossibilidade manifesta de o consumidor pessoa natural, de boa-fé, pagar a totalidade de suas dívidas de consumo, exigíveis e vincendas, sem comprometer seu mínimo existencial, nos termos da regulamentação.

De acordo com o Instituto Brasileiro de Defesa do Consumidor (IDEC), o superendividado é a pessoa que já está com a sua renda comprometida; o consumidor que não tem condições de realizar a quitação dos débitos a ponto de entrar no caráter alimentar, da sua subsistência, ou seja, de quitar contas básicas como alimentação e moradia (DALL'AGNOL, 2019).

Outra alteração do CDC (BRASIL, 1990) pela Lei do Superendividamento diz respeito à prevenção e ao tratamento do superendividamento, a partir do que agora é disposto em seu art. $6^{\circ}$, incs. XI a XIII, a saber:

Art. $6^{\circ}$. [...]:

XI - a garantia de práticas de crédito responsável, de educação financeira e de prevenção e tratamento de situações de superendividamento, preservado o mínimo existencial, nos termos da regulamentação, por meio da revisão e da repactuação da dívida, entre outras medidas;

XII - a preservação do mínimo existencial, nos termos da regulamentação, na repactuação de dívidas e na concessão de crédito;

XIII - a informação acerca dos preços dos produtos por unidade de medida, tal como por quilo, por litro, por metro ou por outra unidade, conforme o caso. [...]. 
Nessa esteira, Galeano e Oliveira (2021) afirmam que o

\begin{abstract}
O superendividamento contém traços de uma morte civil social. O indivíduo com o "nome sujo" e sem margem de crédito tende ao ostracismo. Não consegue montar novos negócios. Enfrenta estigmas ao buscar emprego. Sujeita-se a viver "de favor". Enfim, o superendividamento pode levar o indivíduo a um estado de desesperança e, nas palavras de Raul Seixas, na música Ouro de Tolo, ficar sentado "no trono de um apartamento, com a boca escancarada cheia de dentes, esperando a morte chegar". O motivo é que o superendividamento fulmina o mínimo existencial do indivíduo.
\end{abstract}

Assim sendo, no caso do consumidor endividado, ele pode não conseguir pagar a totalidade da dívida, mas consegue de forma parcial e esses débitos não comprometem a sua subsistência. O consumidor ainda consegue levar uma vida econômica estável. Já no superendividamento não existe meios de quitar os débitos e isso, em alguns casos, compromete a sua subsistência.

Esclarecido esses pontos, a prevenção e o tratamento são alternativas para evitar a exclusão social desse consumidor. Resta claro na lei há o Princípio da Educação Financeira dos Consumidores, o qual, em verdade, se trata do dever de informação. De certa forma, ensinar para esse consumidor as novas formas de consumo e como devem organizar a sua vida econômica para não recair novamente em débitos. A nova lei do superendividamento acaba sendo um alívio necessário organizacional para o consumidor.

Por fim, importante ressaltar que, em tempos de hiperconexão e período pandêmico, aumentou o consumo digital e consequentemente o superendividamento das pessoas. A Internet propicia uma gama de alternativas interessantes para manter o consumidor informado, mas também pode vir a ser utilizada sem boa-fé, de forma que crie mecanismos para fazer as pessoas comprarem mais e mais sem necessidade, conforme proferido anteriormente e aliado aos transtornos mentais no período de isolamento social, que teve um amento vertiginoso.

Em razão disso, a educação financeira se torna uma grande aliada e deve ser ensinada, desde cedo, nas escolas, nos balcões, nas entidades responsáveis, no mundo digital etc., pois o acesso à informação torna-se essencial para diminuir ou eliminar esse consumo impensado e desenfreado. A Lei do Superendividamento reforça princípios essenciais do CDC, bem como, regulamenta a prevenção e o tratamento, sendo um ganho para a sociedade 
ao ensinar a população a um consumo disciplinado e responsável, mesmo com as estratégias dos varejos no e-commerce.

\section{CONCLUSÃO}

O fenômeno da globalização proporcionou o surgimento de tecnologias, as quais diminuíram a distância entre as pessoas no mundo inteiro por meio dos aparatos tecnológicos e a Internet. Dessa forma, tem-se a substituição do modo presencial para o virtual em todos os tipos de relações. Assim, esse avanço possibilita uma comunicação e operações instantâneas e céleres de modo que facilita a rotina das pessoas. Todavia, o ciberespaço virou uma terra sem governo. Um espaço onde não se respeita os direitos e garantias dos cidadãos para termos um Estado Democrático de Direito, pelo que ocorrem atrocidades nas quais as empresas utilizamse do seu poder econômico e estratégias para manipular pessoas no espaço virtual.

A questão em comento, torna-se ainda mais problemática quando há uma manipulação dos dados pessoais e sensíveis dos titulares. Assim, violando direitos constitucionais de intimidade, privacidade e violação dos dados pessoais.

A Internet trouxe muitos benefícios para as relações de consumo, escopo do presente artigo, todavia, também propicia aos cidadãos uma necessidade de comprar cada vez mais por meio da manipulação do e-commerce. Nesse ponto, como visto, é possível, pelo fenômeno do Big Data e manipulação dos algoritmos, obter os mais diversos dados e informações dos indivíduos acerca de determinados assuntos e traçar um perfil de consumidor e de compras.

Ressalta-se a importância da nova Lei do Superendividamento em tempos de isolamento social para propiciar o parcelamento das dívidas dos consumidores e por tratar da prevenção e do tratamento do consumo exacerbado.

Em razão disso, como forma de prevenção e tratamento, como já dito, umas das mais eficazes soluções que deve ser exercida por todos é a educação financeira do consumidor, tendo em vista que a educação é quesito essencial para a resolução dos conflitos. Portanto, é notória a adaptação do consumidor as novas relações de consumo. Todavia, é necessário educar ou reeducar os consumidores já no ensino básico, proporcionar disciplinas de consumo inteligente e economia no ensino fundamental, nas redes sociais, balcões dos consumidores, entre outras formas de divulgação da informação fidedigna para vivermos em uma sociedade mais harmônica, menos imediatista e mais responsável nas relações de consumo. 


\section{REFERÊNCIAS}

BANCO CENTRAL DO BRASIL. Guia de excelência de educação na oferta de serviços financeiros. 2. ed. Brasília: BCB, 2014, v. I. Disponível em: https://www.bcb.gov.br/pre/pef/port/guia_de_excelencia_internet.pdf. Acesso: 17 set. 2021.

BAUMAN, Zygmunt. Globalização. ed. Digital Cidade: Rio de Janeiro, Zahar, 2012. Versão e-book.

BAUMAN, Zygmunt. Vida para consumo. ed. Digital Cidade: Rio De Janeiro, Zahar, 2012. Versão $e$-book.

BIONI, Bruno Ricardo. Proteção de dados pessoais: a função e os limites do consentimento. Rio de Janeiro: GEN Forense, 2018.

BRASIL. Conselho Nacional de Justiça. CNJ Serviço: o que muda com a Lei do Superendividamento? Brasília, 6 ago. 2021. Disponível em: https://www.cnj.jus.br/cnjservico-o-que-muda-com-a-lei-do-superendividamento/. Acesso em: 17 set. 2021.

BRASIL. Lei $\mathbf{n}^{\mathbf{0}} \mathbf{1 4 . 1 8 1}$, de $\mathbf{1}^{\mathbf{0}}$ de julho de 2021. Altera a Lei $\mathrm{n}^{\circ} 8.078$, de 11 de setembro de 1990 (Código de Defesa do Consumidor), e a Lei $\mathrm{n}^{\circ} 10.741$, de $1^{\circ}$ de outubro de 2003 (Estatuto do Idoso), para aperfeiçoar a disciplina do crédito ao consumidor e dispor sobre a prevenção e o tratamento do superendividamento. Disponível em: http://www.planalto.gov.br/ccivil 03/ ato2019-2022/2021/lei/L14181.htm. Acesso em: 17 set. 2021.

BRASIL. Lei $\mathbf{n}^{0}$ 8.078, de 11 de setembro de 1990. Dispõe sobre a proteção do consumidor e dá outras providências. Disponível em: http://www.planalto.gov.br/ccivil 03/LEIS/L8078.htm. Acesso em: 18 set. 2021.

CANTO, Rodrigo Eidelvein do. Vulnerabilidade dos consumidores no comércio eletrônico..ed. 1, São Paulo, Revista dos Tribunais, 2019. Versão $e$-book.

CASTELLS, Manuel. La era de la información: la sociedad red. 2. ed. Madrid: Alianza, 2001, v. 1.

DALL'AGNOL, Laísa. Superendividamento? Saiba o que é e como fugir. Agora, São Paulo, 1 jul. 2019.2 Disponível em: https://agora.folha.uol.com.br/grana/2019/07/superendividamento-saiba-o-que-e-e-comofugir.shtml. Acesso em: 19 set. 2021.

GAGLIANO, Pablo Stolze; OLIVEIRA, Carlos Eduardo Elias de. Comentários à Lei do Superendividamento (Lei $\mathrm{n}^{\circ} 14.181$, de $1^{\circ}$ de julho de 2021) e o princípio do crédito responsável: uma primeira análise. Revista Jus Navigandi, Teresina, a. 26, n. 6575, 2 jul. 2021. ISSN 1518-4862. Disponível em: https://jus.com.br/artigos/91675. Acesso em: 19 set. 2021. 
HAN, Byung-Chul. Sociedade do cansaço. 2. ed.,Rio de Janeiro, Vozes, 2019. Versão $e$ book.

HUI, Yuk. Tecnodiversidade. 1. ed. São Paulo: Ubu, 2020. Versão $e$-book.

MARQUES, Claudia Lima; LIMA, Clarissa Costa de; VIAL, Sophia. Superendividamento dos consumidores no pós-pandemia e a necessária atualização do Código de Defesa do Consumidor. [São Paulo, 2021]. Disponível em: https://www.tjsp.jus.br/download/EPM/Publicacoes/ObrasJuridicas/105dc.pdf?d=637581604679873754. Acesso em: 15 set. 2021.

MASI, Domenico De. O futuro do trabalho: fadiga e ócio na sociedade pós-industrial. Tradução de Yadyr A. Figueiredo. Rio de Janeiro: José Olympio, 1999.

MÁXIMO, Wellton. Agência Brasil explica Lei do Superendividamento. Agência Brasil, Brasília, 30 ago. 2021. Disponível em: https://agenciabrasil.ebc.com.br/economia/noticia/2021-08/agencia-brasil-explica-lei-dosuperendividamento. Acesso em: 17 set. 2021.

SARLET, Ingo Wolfgang. Fundamentos constitucionais: o direito fundamental a proteção de dados. In: BIONI, Bruno; DONEDA, Danilo; SARLET, Ingo Wolfgang; SCHERTEL, Laura; RODRIGUES JR., Otavio Luiz. Tratado de proteção de dados pessoais. Rio de Janeiro: GEN Forense, 2021.

SILVA, Gabriela Rangel da. Tecnologia e relações de trabalho: impactos na vida do trabalhador contemporâneo. Curitiba: Juruá, 2019.

TUCCI, Flavio. Lei do superendividamento comentada - Lei 14.181/2021. 1. ed. Cidade: São Paulo, Saraiva, 2017. Versão e-book. 